\title{
Timing of coronary artery bypass surgery in patients with non-ST-segment elevation myocardial infarction and postoperative outcomes
}

\author{
Ismail Cihan Ozbek ${ }^{1}$, Kenan Sever ${ }^{1}$, Ozkan Demirhan², Denyan Mansuroglu ${ }^{1}$, Muslum Cicek ${ }^{3}$, \\ Ebubekir Emre Men ${ }^{4}$, Fusun Gunesdogdu', Murat Ugurlucan ${ }^{5}$, Murat Basaran ${ }^{5}$, Nuri Kurtoglu
}

${ }^{1}$ Cardiovascular Surgery Department, Gaziosmanpasa Hospital, Istanbul, Turkey
${ }^{2}$ Thoracic Surgery Department, Istanbul Bilim University, Istanbul, Turkey
${ }^{3}$ Anesthesiology Department, Gaziosmanpasa Hospital, Istanbul, Turkey
${ }^{4}$ Cardiology Department, Gaziosmanpasa Hospital, Istanbul, Turkey
${ }^{5}$ Department of Cardiovascular Surgery, Istanbul University Istanbul Medical Faculty,
Istanbul, Turkey

Submitted: 24 June 2013

Accepted: 16 August 2013

Arch Med Sci 2016; 12, 4: 766-771

DOI: 10.5114 /aoms.2014.40546

Copyright @ 2014 Termedia \& Banach

\section{Abstract}

Introduction: The aim of the study was to assess whether a cardiac troponin $\mathrm{T}$ (cTnT) level $1 \mathrm{ng} / \mathrm{ml}$ or below threshold is safe and to evaluate mid-term follow-up results in stable patients with non-ST-segment elevation after acute myocardial infarction.

Material and methods: Among CTnT positive patients who presented to the emergency unit with chest pain and received coronary angiography, 100 patients who underwent isolated coronary artery bypass grafting (CABG) constituted the study group (group 1$)$. The same number of patients $(n=100)$ who were CTnT negative and underwent an isolated CABG operation under elective conditions were selected as the control group (group 2).

Results: Among preoperative criteria, group 1 had significantly higher smoking rates ( $74 \%$ vs. $41 \%, p=0.0001)$, and significantly lower ejection fraction values $(47.1 \pm 8.25,54.69 \pm 8.73, p=0.0001)$. There were no significant differences between the groups with respect to operative parameters. Postoperative follow-up periods were significantly longer in group 1 (23.25 \pm 14 vs. $17.55 \pm 7.95$ months, $p=0.001$ ). Average waiting time for cTnT to drop below the $1 \mathrm{ng} / \mathrm{ml}$ threshold value was $5.73 \pm 2.95(1-12)$ days. Intra-aortic balloon pump use in Groups 1 and 2 was 3\% and 1\%, respectively. There were no hospital mortalities in either group. Mortality rates at mid term were $6 \%$ in both groups.

Conclusions: This study compared two groups positive and negative for preoperative CTnT. The findings show that it is safe to wait until CTnT levels decrease to the $1 \mathrm{ng} / \mathrm{ml}$ threshold value in CTnT positive patients having a stable course. This waiting period is not very long, which is significant with respect to potential complications.

Key words: myocardial infarction, non-ST-segment elevation, coronary artery bypass grafting, timing, troponin-T.

\section{Introduction}

It has been clearly shown in numerous studies that emergency coronary artery bypass grafting (CABG) after acute coronary syndrome (ACS)

\author{
Corresponding author: \\ Ismail Cihan Ozbek MD \\ Cardiovascular Surgery \\ Department \\ Gaziosmanpasa Hospital \\ Istanbul, Turkey \\ Phone: +905325864852 \\ Fax: +9021234342 21 \\ e-mail: ozbekmd@gmail.com
}


carries high morbidity and mortality rates. The management strategy is clear in unstable patients who have indications for emergency surgery; however, the timing of surgery in stable ST-segment-elevation myocardial infarction (STEMI) and non-ST-segment-elevation myocardial infarction (NSTEMI) patients remains controversial [1]. The limited number of clinical studies on this issue have reported that surgery during the early period may increase morbidity and mortality. However, depending on different studies, the definition of the early period varies between the first $6 \mathrm{~h}$ to 1 month after hospitalization. It is possibly due to this uncertainty that some studies have found CABG in the early phase to be related to increased morbidity and mortality, whereas others did not find such an increased risk [2-8].

Cardiac troponins are highly sensitive and specific laboratory tests which indicate myocardial injury. Diagnosing patients with ACS and determining their treatment alternatives provide valuable information on the prognosis of these patients $[9,10]$. There are numerous studies which have shown an association between high preoperative and postoperative troponin levels associated with increased morbidity and mortality rates in patients undergoing CABG [11-14]. This raises the possibility that cardiac troponin levels may be used as a marker for the timing of CABG operations. Thielmann et al. [13] found that the subgroup of patients with NSTEMI with troponin I values above $1.5 \mathrm{ng} / \mathrm{ml}$ had twice the mortality than those below this level, and the CABG operation could be performed with acceptable risks in patients with troponin I levels under $1.5 \mathrm{ng} / \mathrm{ml}$. For the last 5 years at our institution our practice has been to wait for the cardiac troponin $\mathrm{T}$ (cTnT) to drop below $1 \mathrm{ng} / \mathrm{ml}$ and perform CABG once the acute phase is over.

In this study, we aimed to investigate the safety of this threshold value and discuss our mid-term results in the light of the current literature.

\section{Material and methods}

Patients who presented to the emergency department of our institution between January 2008 and January 2013 were reviewed. Patients were divided into two groups: group 1 ( $n=100$ patients) comprising patients with positive cTnT levels who underwent the CABG procedure; and group 2 comprising the same number of patients, randomly chosen, with negative CTnT levels who underwent the CABG procedure during the same period. Randomization of the patients in group 2 was arranged by the free use web-based system (http:// www.tufts.edu/ gdallal/PLAN.HTM). One hundred patients could be randomized out of 228 patients and remaining patients operated during the same period of time were not taken into account. None of the patients in group 2 had previous STEMI or NSTEMI in their past medical history. Patients who had continuous chest pain while still on medical treatment, were hemodynamically unstable, had life-threatening severe arrhythmias, had post-MI mechanical complications or left main coronary artery lesion of $50 \%$ or above, had primary percutaneous intervention ( $\mathrm{PCI}$ ) during coronary angiography, or had a history of a prior CABG operation were excluded from the study. Patients operated off-pump were also excluded for randomization purposes. The patients in group 1 were not discharged from the hospital until their surgery and received anticoagulant treatment with low molecular weight heparin. Troponin levels were assessed daily, and the patients were operated when the cTnT level dropped below $1 \mathrm{ng} / \mathrm{ml}$. Troponin level measurements were made by the electrochemiluminescence method using a Troponin T hs kit (Roche Diagnostics GmbH, Mannheim, Germany).

\section{Surgical procedure}

All the patients were operated through full median sternotomy. The grafts were prepared after opening the sternum. The ascending aorta and two-stage right atrium cannulations were performed. Systemic heparinization with $300 \mathrm{U} / \mathrm{kg}$ heparin was made, and cardiopulmonary bypass was initiated when activated clotting time (ACT) reached $>400 \mathrm{~s}$. Non-pulsatile perfusion, coated tubing set and membrane oxygenators were used with moderate hypothermia $\left(32-34^{\circ} \mathrm{C}\right)$. Antegrade or optional retrograde cold blood cardioplegia was applied for myocardial protection.

\section{Definitions}

The NSTEMI is defined as transient ST-segment depression $\geq 1 \mathrm{~mm}$ or $\mathrm{T}$ wave inversion in 2 or more precordial leads in a patient with chest pain, dyspnea, or lethargy accompanied by elevated troponin and/or creatine kinase-myocardial band (CK-MB).

The presence of diabetes, hypertension, and smoking were determined from the patient histories. Cholesterol levels above $200 \mathrm{mg} / \mathrm{ml}$ were accepted as hyperlipidemia, body mass index over $30 \mathrm{~kg} / \mathrm{m}^{2}$ was accepted as obesity, forced expiratory volume exhaled at the end of $1 \mathrm{~s}$ $\left(\mathrm{FEV}_{1}\right) /$ forced vital capacity $(\mathrm{FVC})<50 \%$ was accepted as chronic obstructive pulmonary disease (COPD), and creatinine levels above $0.2 \mu \mathrm{mol} / \mathrm{l}$ were accepted as renal disease. The presence of a $50 \%$ or greater stenosis of the carotid arteries on preoperative routine carotid Doppler ultrasonography or other established peripheral artery diseases were accepted as criteria for peripheral vascular disease. In the definition of coronary ar- 
tery disease; '0’ was used for left main coronary disease (<50\% stenosis), ' 1 ', '2' and ' 3 ' for single-, two- and three-vessel disease, respectively. Use of adrenaline, dobutamine, dopamine and noradrenaline for inotropic support was recorded numerically from 1 to 4 .

\section{Parameters}

Both groups were compared with respect to preoperative parameters including demographic data (age, sex), risk factors (diabetes mellitus, hypertension, hyperlipidemia, obesity, smoking), comorbidities (COPD, peripheral vascular disease, renal disease), the extent of coronary artery disease, left ventricle ejection fraction (EF), and EuroSCORE; operative parameters including cross clamp time and perfusion time, number of grafts, and use of the left internal mammary artery (LIMA); and postoperative parameters including duration of ventilatory support, length of stay in the intensive care unit and hospital, requirement for blood and blood product transfusion, revision, inotropic agent use due to low cardiac output, and follow-up period findings. In group I, peak cTnT levels and levels at the onset of surgery, time waited before CTnT dropped to $1 \mathrm{ng} / \mathrm{ml}$ or below, and problems encountered during follow-up were recorded. The patients were called for follow-up at the postoperative $1^{\text {st }}$ week, $3^{\text {rd }}$ and $6^{\text {th }}$ weeks, $6^{\text {th }}$ month and every 6 months thereafter. Patients who did not come to the control visit were contacted by telephone and final conditions were recorded.

\section{Statistical analysis}

Statistical evaluation was performed with the Number Cruncher Statistical System (NCSS) 2007 Statistical Software (Utah, USA) program. Evaluation of the data was made with descriptive statistical methods (mean, standard deviation), the two groups were compared with independent $t$ test, and the qualitative data were compared with the $\chi^{2}$ test. The results were considered significant for $p<0.05$

\section{Results}

Analysis of preoperative basic characteristics showed that the male sex was predominant in both groups ( $82 \%$ in group 1 , and $72 \%$ in group 2 ). There were no statistically significant differences between the groups with respect to age and sex. Analysis of risk factors showed no significant difference except for smoking. Smoking was significantly higher in group 1 compared to group 2 ( $74 \%$ and $41 \%$, respectively; $p=0.0001)$. The differences between comorbidity, extent of coronary artery disease, and EuroSCORE values were not significant. Ejection fraction values were sig- nificantly lower in group 1 compared to group 2 (47.1 $\pm 8.25,54.69 \pm 8.73 ; p=0.0001)$ (Table I). Comparison of operative data showed no significant differences in cross clamp and perfusion times, number of grafts, and use of LIMA (Table I). Evaluation of postoperative values did not show significant differences in duration of ventilatory support, length of stay in the intensive care unit or the hospital, blood and blood product transfusion requirement, revision and use of cardiac inotropic agents. Follow-up periods were significantly longer in group $1(23.3 \pm 14$ months and $17.6 \pm 8$ months; $p=0.001$ ) (Table I). In group 1 , the highest cTnT level prior to surgery was $3.2 \pm 1.8 \mathrm{ng} / \mathrm{dl}$ (11.95-1.13), and cTnT level on the day of surgery was $0.6 \pm 0.3 \mathrm{ng} / \mathrm{dl}$ (1.00-0.01). The average time elapsed for the cTnT levels to drop below the $1 \mathrm{ng} / \mathrm{ml}$ threshold level was $5.7 \pm 2.95$ (1-12) days. Three patients in group 1 and 1 patient in group 2 required intra-aortic balloon pump (IABP) support. There were no hospital mortalities in either group. Complications seen within the follow-up period were found to be $10 \%$ and $8 \%$ for myocardial infarction and unstable angina, $12 \%$ and $14 \%$ for control angiography, $3 \%$ and $2 \%$ for percutaneous coronary intervention, $4 \%$ and $3 \%$ for cardiac mortality (Figure 1), and $2 \%$ and $3 \%$ for noncardiac mortality, in group 1 and 2, respectively. The survival was calculated to be $94 \%$ for both groups (Figure 1, Table II).

\section{Discussion}

The timing of surgical revascularization after acute myocardial infarction (AMI) is still controversial. Emergency $C A B G$ is recommended in patients who have undergone failed or complicated $\mathrm{PCl}$, have signs of ischemia despite medical treatment, complications of $\mathrm{AMI}$, life-threatening arrhythmias and/or hemodynamic instability. Early revascularization may prevent further worsening of the ventricular functions by limiting the progression of the infarct area. It has a positive contribution to ventricular remodeling as well. On the other hand, hemorrhagic complications due to reperfusion injury may widen the infarct area, increase scar tissue and affect the recovery process negatively. Severe ventricular arrhythmias may be encountered following reperfusion. Collateral blood is significantly variable from one patient to another, and affected negatively by hypotension, arrhythmias, and increased left ventricular end diastolic pressure during AMI. Therefore prevention of these arrhythmias and hemodynamic control carry vital significance. The control of symptoms and maintenance with aggressive medical treatment is suggested as a priority [1].

In a series of 4676 patients operated in the early period after AMI, Weiss et al. found greater 
Timing of coronary artery bypass surgery in patients with non-ST-segment elevation myocardial infarction and postoperative outcomes

Table I. Pre-, intra-, post-operative characteristics of the enrolled patient population

\begin{tabular}{|c|c|c|c|c|c|}
\hline \multicolumn{6}{|c|}{ Preoperative characteristics of the patients in the groups } \\
\hline Demographics $^{1}$ & Group $1(n=100)$ & Group $2(n=100)$ & $t$ & $\chi^{2}$ & $P$-value \\
\hline Age [years] & $58.3 \pm 11.6$ & $61.0 \pm 8.3$ & -1.92 & & 0.057 \\
\hline Female gender & $18 \%$ & $28 \%$ & & 2.28 & 0.130 \\
\hline \multicolumn{6}{|l|}{ Cardiovascular risk factors: } \\
\hline Diabetes mellitus & $38 \%$ & $45 \%$ & & 1.01 & 0.315 \\
\hline Hypertension & $63 \%$ & $80 \%$ & & 2.82 & 0.082 \\
\hline Hyperlipidemia & $46 \%$ & $45 \%$ & & 0.02 & 0.887 \\
\hline Obesity $^{2}$ & $25 \%$ & $26 \%$ & & 0.03 & 0.871 \\
\hline Smoking history & $74 \%$ & $41 \%$ & & 22.28 & 0.0001 \\
\hline \multicolumn{6}{|l|}{ Comorbidities: } \\
\hline COPD & $10 \%$ & $14 \%$ & & 0.76 & 0.384 \\
\hline PVD & $14 \%$ & $15 \%$ & & 0.04 & 0.841 \\
\hline Renal disease ${ }^{3}$ & $13 \%$ & $12 \%$ & & 0.05 & 0.831 \\
\hline \multicolumn{6}{|l|}{ Extent of CAD: } \\
\hline Left main stem disease* & $16 \%$ & $10 \%$ & & & \\
\hline One vessel disease & $7 \%$ & $7 \%$ & & & \\
\hline Two vessel disease & $16 \%$ & $26 \%$ & & & \\
\hline Three vessel disease & $61 \%$ & $57 \%$ & & 3.9 & 0.272 \\
\hline LVEF & $47.1 \pm 8.3$ & $54.7 \pm 8.7$ & -6.32 & & 0.0001 \\
\hline EuroSCORE & $2.2 \pm 1.9$ & $2.1 \pm 1.8$ & 0.15 & & 0.879 \\
\hline \multicolumn{6}{|l|}{ Operative characteristics: } \\
\hline ACC time [min] & $43.7 \pm 20.6$ & $45.1 \pm 13.0$ & -0.58 & & 0.560 \\
\hline CPB time [min] & $73.6 \pm 33.5$ & $72.8 \pm 19.0$ & 0.21 & & 0.834 \\
\hline Grafts per patient & $3.2 \pm 1.1$ & $3.1 \pm 0.9$ & 0.71 & & 0.476 \\
\hline IMA grafts & $99 \%$ & $97 \%$ & 1.02 & & 0.312 \\
\hline \multicolumn{6}{|l|}{ Postoperative characteristics: } \\
\hline Ventilation time $[\mathrm{h}]$ & $9.9 \pm 7.7$ & $9.4 \pm 3.3$ & 0.70 & & 0.488 \\
\hline ICU stay [day] & $1.8 \pm 1.2$ & $1.8 \pm 0.8$ & 0.35 & & 0.724 \\
\hline Hospital stay [day] & $6.1 \pm 2.0$ & $5.67 \pm 1.0$ & 1.74 & & 0.083 \\
\hline Blood transfusion [U] & $1.6 \pm 0.9$ & $1.5 \pm 1.0$ & 0.14 & & 0.886 \\
\hline Revision rate & $3 \%$ & $2 \%$ & 0.21 & & 0.651 \\
\hline IABP support, $n$ & 3 & 1 & & & 0.064 \\
\hline \multicolumn{6}{|l|}{ Inotrope use: } \\
\hline No inotrope & $37 \%$ & $49 \%$ & & 2.93 & \\
\hline One inotrope & $50 \%$ & $35 \%$ & & 4.60 & \\
\hline Two inotropes & $11 \%$ & $16 \%$ & & 1.07 & \\
\hline Three inotropes & $2 \%$ & $0 \%$ & & 2.02 & \\
\hline Following time [months] & $23.3 \pm 14$ & $17.6 \pm 8.0$ & 3.54 & & 0.001 \\
\hline
\end{tabular}

CAD - coronary artery disease, COPD - chronic obstructive pulmonary disease, PVD - peripheral vascular disease, LVEF - left ventricular ejection fraction, $A C C$ - aortic cross-clamp, ACC - aortic cross-clamp, CPB - cardiopulmonary bypass, IMA - internal mammary artery, $I A B P$ - intra-aortic balloon pump support; ${ }^{1}$ Continuous data are presented as mean \pm standard deviation, ${ }^{2}$ body mass index $>30 \mathrm{~kg} / \mathrm{m}^{2}$, ${ }^{3}$ serum creatinine $>0.2 \mathrm{mmol} / \mathrm{l},{ }^{*}<50 \%$ stenosis. 


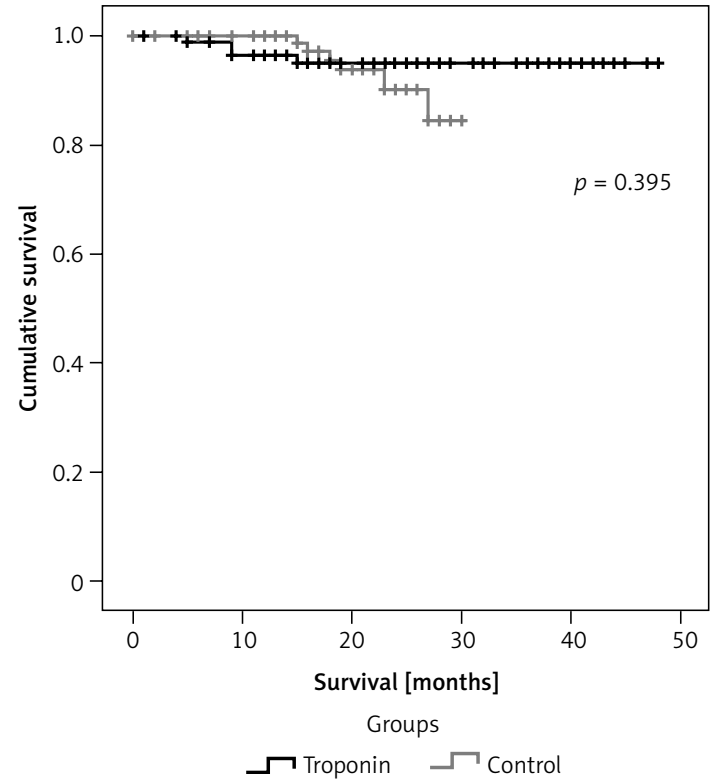

Figure 1. Kaplan-Meier curve for mid-term mortality

mortality in the group of patients operated within the first 2 days compared to those operated on the $3^{\text {rd }}$ day or later. The authors suggested to wait at least 3 days before CABG, except for emergency conditions [15]. Thielmann et at. found an 8.7\% hospital mortality rate in patients with AMI with ST elevation ( $n=138)$. In the same study, analysis of symptom onset, timing of surgery and hospital mortality rates showed that the highest mortality rates were between $7 \mathrm{~h}$ and $23 \mathrm{~h}(23.8 \%)$, and the lowest were between 8 and 14 days (2.4\%). The hospital mortality rates in another study were found to between 3.0 and $6.6 \%$ in AMI patients with high cTnl levels and non-ST segment elevation [13]. In a similar study, Cresswell et al. [6] observed that the greatest operative mortality after AMI was seen in 11 patients (9.1\%) operated within the first $6 \mathrm{~h}$. In the same study, the operative mortality decreased to $2.9 \%$ in 1023 patients operated 6 weeks later, and the total mortality in 3942 patients was $3.5 \%$. The mortality of 1646 non-AMI patients who underwent elective surgery was $2.1 \%$ [6]. In summary, the hospital mortality of AMI patients who require surgical revascularization approaches the rates of an elective group of patients if they can be kept stable during the acute phase.

When patients with NSTEMI are examined separately, it is seen that the difference in mortalities between the early and late revascularization groups is smaller, or there is no difference according to some studies. In a retrospective study including 283 NSTEMI patients, Braxton et al. found no difference between the mortality rates in patients undergoing CABG before or after $48 \mathrm{~h}$, and concluded that these patients could be operated
Table II. Complications and mortality in follow-up period

\begin{tabular}{lcc|}
\hline Characteristics & Group 1 & Group 2 \\
\hline MI, unstable angina & $10 \%$ & $8 \%$ \\
\hline Control angiography & $12 \%$ & $14 \%$ \\
\hline $\mathrm{PCl}$ & $3 \%$ & $2 \%$ \\
\hline Cardiac death & $4 \%$ & $3 \%$ \\
\hline Non-cardiac death & $2 \%$ & $3 \%$ \\
\hline Survival & $94 \%$ & $94 \%$ \\
$\begin{array}{l}\text { MI- myocardial infarction, } \mathrm{PCl}-\text { percutaneous coronary } \\
\text { intervention. }\end{array}$
\end{tabular}

at any time after MI with mortality rates similar to those of control patients who did not sustain MI (3.5\% vs. $2.4 \%, p$ not significant) [2]. Gertler et al. [3] investigated the same question, and found that there was no difference in mortalities when patients were operated within the first 12 days or afterwards. Parikh et al. [4] found similar mortality rates in 2647 NSTEMI patients who underwent CABG within the first $48 \mathrm{~h}$ after admission to the hospital or later. Deyell et al. studied a cohort of 1454 patients. Patients who underwent CABG during the early phase between 2 and 7 days after $\mathrm{MI}$ had increased mortality compared to those operated during the moderate (8-14 days) and late (15-60 days) phases [5]. Due to these inconsistent results of the studies, stable patients with NSTEMI often wait for weeks before bypass surgery, which results in unnecessary consumption of resources. Also, stable patients who are offered to undergo surgery after coronary angiography carry the risk of sustaining a new Ml at home when they are discharged from the hospital. The most logical approach appears to be operating on these patients after waiting for a reasonable time and without discharging them. However, what should be the reasonable time? In most studies, the time that elapsed from hospital admission to the operation is used as a threshold value. In these studies, the definition of post-MI early revascularization ranges between $6 \mathrm{~h}$ and 1 month, thereby making it difficult to evaluate study results. Inability to make an objective assessment of the time of $\mathrm{MI}$ in patients with NSTEMI causes another problem in the evaluation of studies.

The roles of cardiac troponins in predicting the preoperative and postoperative mortality and morbidity have been demonstrated in various studies [9-11]. Filizcan et al. [14] showed that cardiac troponin levels were one of the predictive factors for hospital mortality in AMI patients with ST-segment elevation. Paparella et al. [16] similarly showed that cTnl levels before surgery played a role in the increase of myocardial injury after surgery and negatively affected mid-term mortality and morbidity. Therefore, it may be predicted that waiting for 
cTnT levels to fall to a certain level may decrease postoperative morbidity and mortality. In patients with NSTEMI, waiting for the CTnT to decrease to a quantitative level $(1 \mathrm{ng} / \mathrm{ml})$ eliminates most of the uncertainties stated above. The mortality of isolated CABG is below $1 \%$ in most studies. In one series, hospital mortality rates in 2337 patients with low risk and 2272 patients with moderate risk were found to be $0.9 \%$ and $1.7 \%$, respectively [17]. In our study, the absence of hospital mortality in both groups is similar to other studies [18-20] with respect to the troponin negative group 2, and also shows that it is more successful than other series with respect to troponin positive group 1 patients. During the follow-up period the rates for myocardial infarction, unstable angina, angiography for control purposes, percutaneous coronary intervention, cardiac and non-cardiac mortalities were as expected, and $94 \%$ survival rates were found to be satisfactory.

In conclusion, the results of the current research indicated the safety of delaying CABG until the cTnT levels fall below the $1 \mathrm{ng} / \mathrm{ml}$ threshold in patients with a stable course after AMI. The waiting period is usually not very long, which is important for the prevention of complications that may develop as a consequence of AMI.

\section{Acknowledgments}

The authors would like to convey sincere gratitude to Mr. Robert Moore for the language revision of the manuscript.

\section{References}

1. Hillis LD, Smith PK, Anderson JL, et al. 2011 ACCF/AHA Guideline for Coronary Artery Bypass Graft Surgery: A Report of the American College of Cardiology Foundation/American Heart Association Task Force on Practice Guidelines Writing Committee Members. Circulation 2011; 124: e652-735.

2. Braxton JH, Hammond GL, Letsou GV, et al. Optimal timing of coronary artery bypass graft surgery after acute myocardial infarction. Circulation 1995; 92 (9 Suppl): 1166-8.

3. Gertler JP, Elefteriades JA, Kopf GS, Hashim SW, Hammond GL, Geha AS. Predictors of outcome in early revascularization after acute myocardial infarction. Am J Surg 1985; 149: 441-4.

4. Parikh SV, de Lemos JA, Jessen ME, et al.; CRUSADE and ACTION Registry-GWTG Participants. Timing of in-hospital coronary artery bypass surgery for non-STsegment elevation myocardial infarction patients. JACC Cardiovasc Interv 2010; 3: 419-27.

5. Deyell MW, Ghali WA, Ross DB, Zhang J, Hemmelgarn BR; Alberta Provincial Project for Outcome Assessment in Coronary Heart Disease (APPROACH) Investigators. Timing of nonemergent coronary artery bypass grafting and mortality after non-ST elevation acute coronary syndrome. Am Heart J 2010; 159: 490-6.
6. Creswell LL, Moulton MJ, Cox JL, Rosenbloom M. Revascularization after acute myocardial infarction. Ann Thorac Surg 1995; 60: 19-26.

7. Deeik RK, Schmitt TM, Ihrig TG, Sugimoto JT. Appropriate timing of elective coronary artery bypass graft surgery following acute myocardial infarction. Am J Surg 1998; 176: 581-5.

8. Lee DC, Oz MC, Weinberg AD, Lin SX, Ting W. Optimal timing of revascularization: transmural versus nontransmural acute myocardial infarction. Ann Thorac Surg 2001; 71: 1198-204.

9. Alpert JS, Thygesen K, Antman E, Bassand JP. Myocardial infarction redefined-a consensus document of The Joint European Society of Cardiology/American College of Cardiology Committee for the redefinition of myocardial infarction. J Am Coll Cardiol 2000; 36: 959-69.

10. Antman EM, Tanasijevic MJ, Thompson B, et al. Cardiac-specific troponin I levels to predict the risk of mortality in patients with acute coronary syndromes. N Engl J Med 1996; 335: 1342-9.

11. Amin AP, Mukhopadhyay E, Napan S, Mamtani M, Kelly RF, Kulkarni H. Value of early cardiac troponin I to predict long-term adverse events after coronary artery bypass graft surgery in patients presenting with acute coronary syndromes. Clin Cardiol 2009; 32: 386-92.

12. Thielmann M, Neuhäuser M, Marr A, et al. Predictors and outcomes of coronary artery bypass grafting in ST elevation myocardial infarction. Ann Thorac Surg 2007; 84: 17-24.

13. Thielmann M, Massoudy P, Neuhäuser M, et al. Prognostic value of preoperative cardiac troponin I in patients with non-ST-segment elevation acute coronary syndromes undergoing coronary artery bypass surgery. Chest 2005; 128: 3526-36.

14. Filizcan U, Kurc E, Cetemen S, et al. Mortality predictors in ST-elevated myocardial infarction patients undergoing coronary artery bypass grafting. Angiology 2011; 62: 68-73.

15. Weiss ES, Chang DD, Joyce DL, Nwakanma LU, Yuh DD. Optimal timing of coronary artery bypass after acute myocardial infarction: a review of California discharge data. J Thorac Cardiovasc Surg 2008; 135: 503-11.

16. Paparella D, Scrascia G, Paramythiotis A, et al. Preoperative cardiac troponin I to assess midterm risks of coronary bypass grafting operations in patients with recent myocardial infarction. Ann Thorac Surg 2010; 89: 696-703.

17. Sönmez B, Arbatı H, Demirsoy E. In: Textbook of cardiovascular surgery. Duran E (eds.). 2000; Vol. 2; Chapter 92: 1343-400.

18. Sadowski M, Janion-Sadowska A, Gąsior M, Gierlotka M, Janion M, Poloński L. Higher mortality in women after ST-segment elevation myocardial infarction in very young patients. Arch Med Sci 2013; 9: 427-33.

19. Irzmański R, Piechota M, Barylski M, et al. NT-proBNP in patients after acute coronary syndrome with ST segment elevation subjected to early posthospitalization cardiologic rehabilitation. Arch Med Sci 2006; 2: 262-7.

20. Kołodziej K, Drożdż J, Kurpesa M, Bednarkiewicz Z, Krzemińska-Pakuła M. Prognosis and long-term observation of a group of patients with acute coronary syndromes without ST-elevation (ACS-NSTEMI). Arch Med Sci 2006; 2: 164-70. 